\title{
The Spinning Tools from Sunget, Anaro and Savidug
}

\author{
Judith Cameron
}

This chapter describes the spindle whorls recovered from the sites of Sunget, Anaro and Savidug Dune Site. The majority belong to the period between approximately $1200 \mathrm{BC}$ and AD 1.

The technology of textiles revolves around the preparation of fibres to produce thread suitable for loom weaving. During the Neolithic period in South China, a simple device called the hand spindle was developed for this purpose. Comprised of a weight (whorl) and a shaft (rod) designed to keep the weight vertical, the hand spindle twists fibres mechanically to extend their length before being woven on looms. While the length of plant fibres can also be extended manually through hand twisting or knotting, the hand spindle twists fibres much faster and more efficiently. Spinning also increases the tensile strength of fibres ensuring that woven threads neither break nor unravel. For these reasons, the invention of the hand spindle in many parts of the world has been heralded as a Neolithic revolution in textile technology.

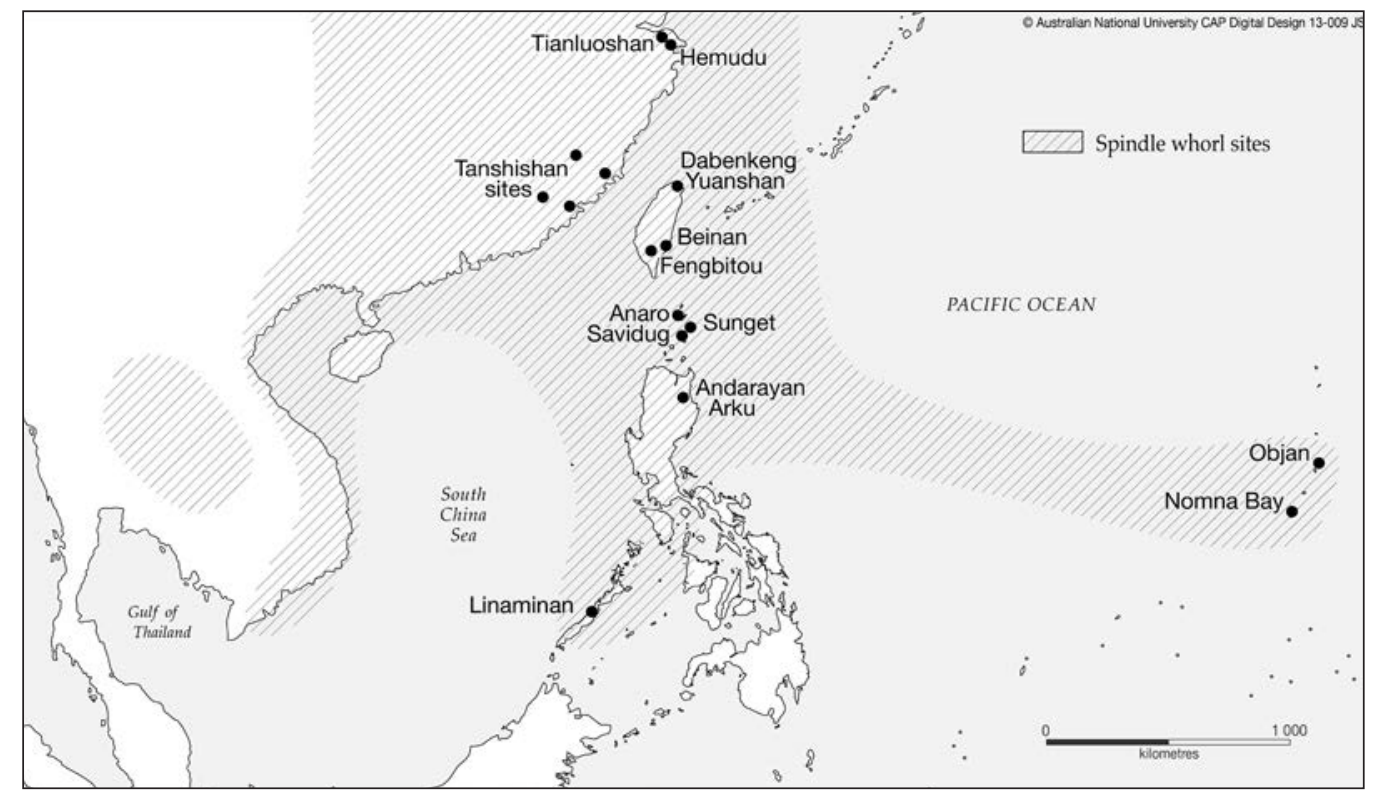

Figure 7.1. The archaeological distribution of spindle whorls in Neolithic Southeast Asia (updated from Cameron 2001: Fig.1).

Source: Map preparation by ANU College of Asia and the Pacific, CartoGIS. 


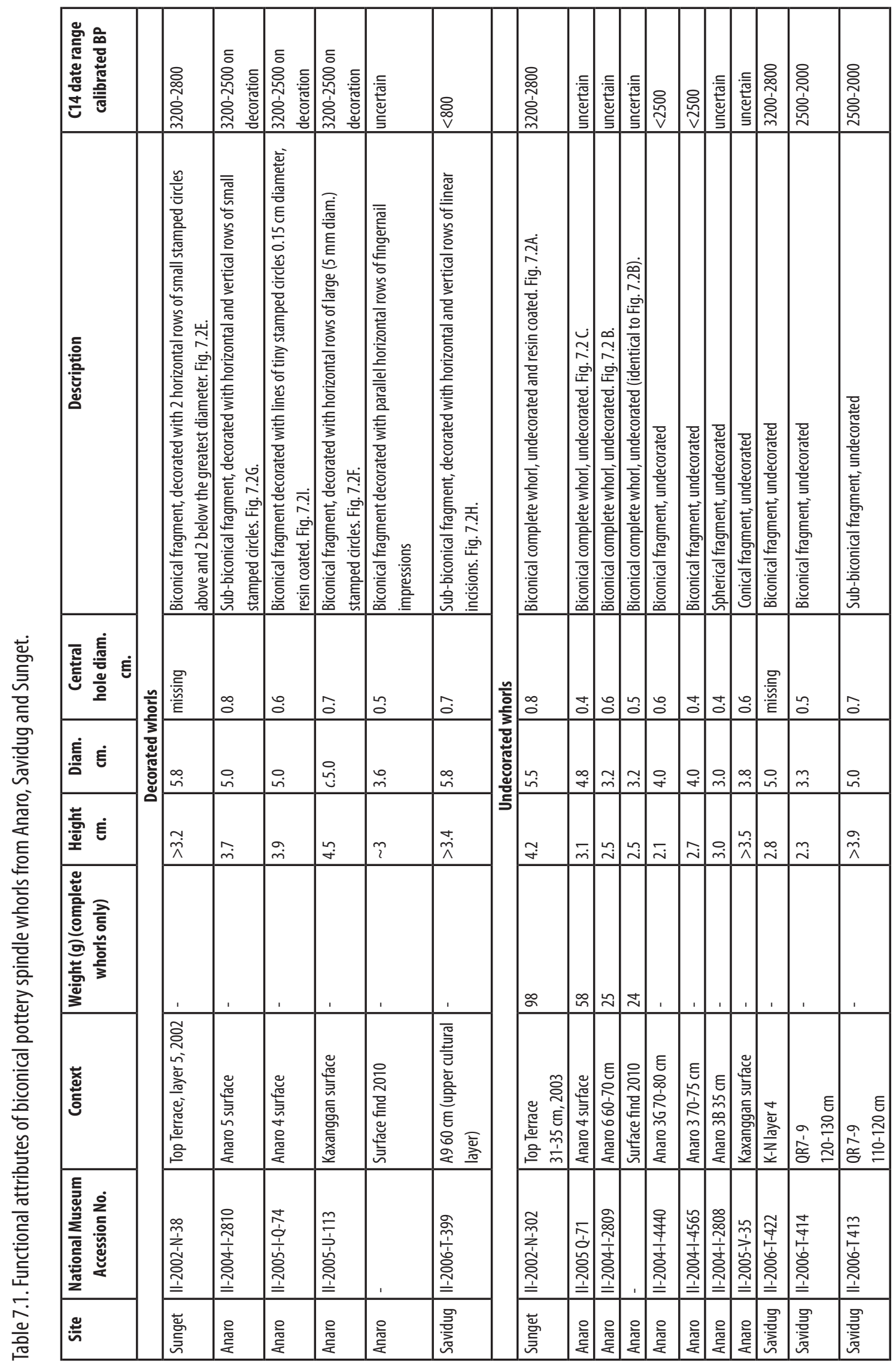


Previously, I have traced the prehistoric origins and movement of spinning technology from Southeast China into Taiwan, Island Southeast Asia and the Marianas (Cameron 2001, 2002). This research showed the distribution and dramatic decline of spinning data south of Taiwan. Although a small number of whorls have been found in northern Luzon, only a very few isolated examples have been found further south in Island Southeast Asia (Fig. 7.1). This can be explained by two inter-related environmental factors. Firstly, the hot and wet tropical climate south of Luzon was not conducive to the cultivation of some of the fibre-producing plants upon which textile technology developed. Secondly, these tropical islands hosted species such as Curculigo latifolia (lemba) and Musa textilis (abaca), whose fibres were knotted or twisted, rather than spun, before being woven on looms.

This chapter provides the results of an analysis of a small assemblage of spindle whorls from the Batanes sites of Sunget, Anaro and Savidug. The functional attributes of the tools in the assemblage were measured (Table 7.1), and decorative elements were recorded where present (Fig. 7.2). The results are compared with excavated parallels from Taiwan and the Cagayan Valley in Luzon. Because of the strategic position of the Batanes between Taiwan and the Philippines, the Batanes whorls provide insights into the introduction of textile technology into Island Southeast Asia.

The largest number of whorls found in Batanes come from the site of Anaro on Itbayat Island. Significantly perhaps, the oldest Itbayat assemblages, from Torongan and Reranum caves (2000$1000 \mathrm{BC}$ ), were devoid of whorls, although these sites both have very small artefact assemblages so this could just be sample size bias. In total, four complete whorls and seven fragments were found at Anaro. These ranged in size from 3.0 to $5.0 \mathrm{~cm}$ in diameter, which is within the range of prehistoric Chinese and Southeast Asian whorls. All items were made from the same type of fired earthenware as the other pottery from the site. Many of the whorls from Anaro (as also at Sunget and Savidug) are biconical in shape, although one is sub-conical with a slight tendency to a tear-drop shape, one is conical, and another is spherical. The majority were decorated, either with fingernail impressions, incised lines, or stamped circles. One resin coated whorl (Fig. $7.2 \mathrm{I}$ ) is similar to the resin coated undecorated whorl from Sunget shown in Fig. 7.2 A. The stamped circle motifs at Anaro and Sunget could have been applied using stems of Calamus mollis (rattan), or bamboo.

Unfortunately, the decorated specimens from Anaro were all surface finds, but their zoned stamped circle motifs relate them to the lowest cultural phase at Anaro (Phase 2, older subphase, as defined in chapter 5), between 1200 and $500 \mathrm{BC}$ and thus contemporary with the whorls from Sunget. Interestingly, the three biconical specimens found in the excavations at Anaro were all plain, and date stratigraphically from the younger subphase of Phase 2, after 500 BC.

Sunget on Batan Island produced three whorls, one fragment being decorated with four rows of stamped circles around the greatest diameter (Fig. 7.2 E). The resin coated specimen from 31-35 $\mathrm{cm}$ in the top terrace (Fig. 7.2 A) has a high mineral content with traces of quartz.

Savidug Dune Site on Sabtang Island produced four whorls, three plain biconical examples from the lower cultural layer, and one (Fig. 7.2 H) from the upper cultural layer decorated with short incisions. Interestingly, this younger specimen has the same layout of decoration as the presumed much older specimen shown in Fig. 7.2 G from Anaro 5. This suggests they both belong to a continuing technological tradition. But, by the time of the Savidug upper layer, the stamped circle fashion had completely died so a different kind of short incision was preferred.

Savidug is also located near a stream which was probably used in fibre preparation. As bast fibres need to be washed many times during fibre processing, proximity to fresh water is important. Surprisingly, no whorls were found inside the burial jars that characterize the Savidug site. 


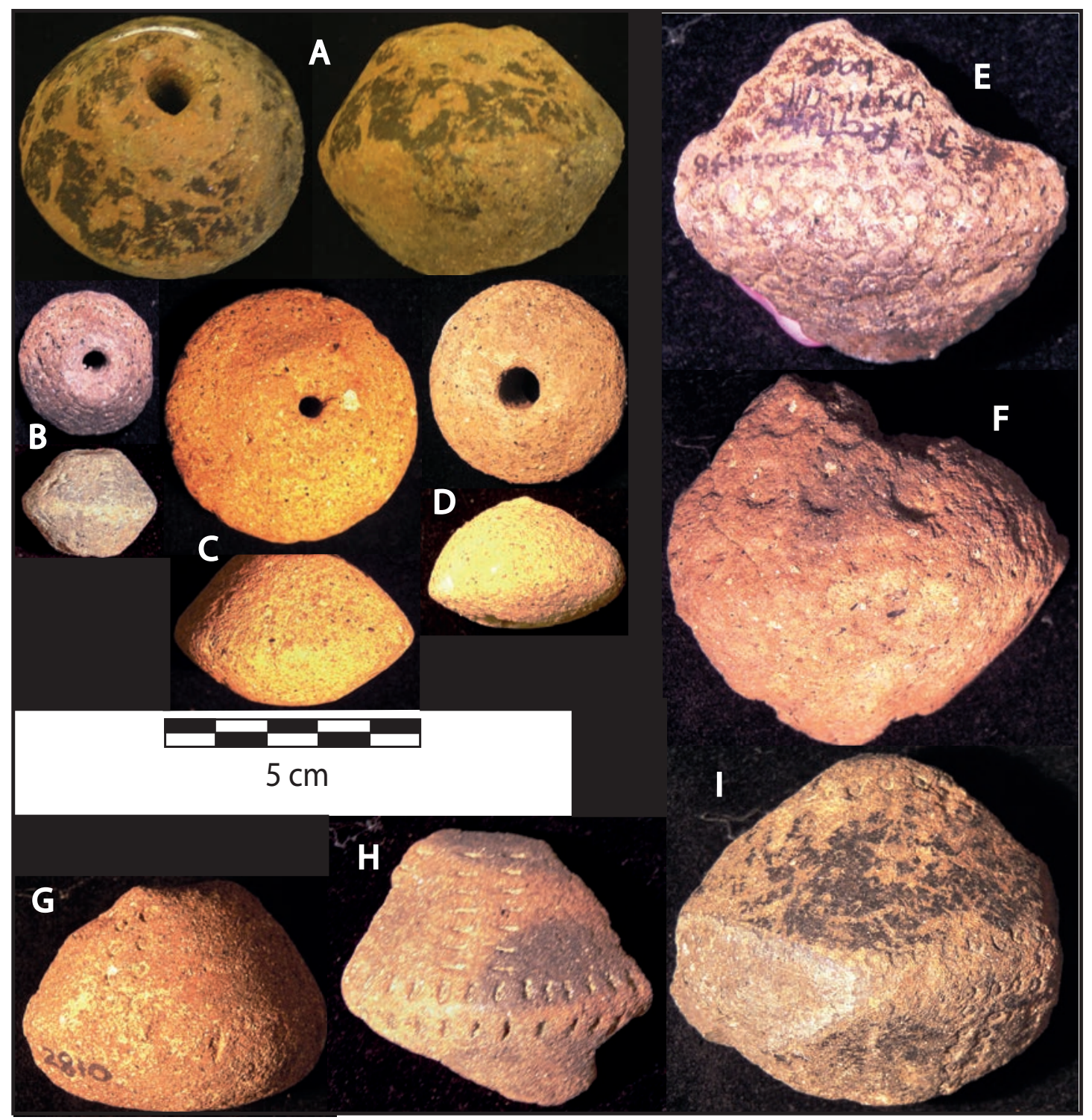

Figure 7.2. Baked clay spindle whorls from Sunget, Anaro and Savidug. The $5 \mathrm{~cm}$ scale only refers to the four complete whorls at top left (A to D). The others have been enlarged to show their decoration (dimensions are given in Table 7.1).

A. Sunget Top Terrace, $31-35 \mathrm{~cm}$;

B. Anaro 6, 60-70 cm;

C. Anaro 4 surface;

D. sub-biconical whorl from Andarayan, Cagayan Valley;

E. Sunget Top Terrace with 4 rows of stamped circles;

F. Anaro surface (Kaxanggan) with very deeply impressed circles;

G. Anaro 5 surface with paired vertical rows each with 4 small stamped circles;

H. Savidug A9 $60 \mathrm{~cm}$ (upper cultural layer) with horizontal and vertical rows of linear incisions;

I. Anaro 4 surface with resin coat and horizontal and vertical rows of small stamped circles.

$\mathrm{G}, \mathrm{H}$ and $\mathrm{I}$ have the same design structure, even though $\mathrm{H}$ is about 1000 years or more younger in date. 


\section{Discussion}

Can these prehistoric spinning tools from the Batanes be linked to any prehistoric groups? This analysis clearly shows that the whorls recovered during the Batanes excavations belonged to a prehistoric textile technology tradition that had roots in South China. The most diagnostic functional attribute of the Batanes whorls is shape. Significantly, most of the whorls in the assemblage are biconical or sub-biconical. Although some basic spindle whorl types are generic, Cameron (2002) previously demonstrated that biconical spindle whorl shapes are so specific culturally that they can be used to trace the movement of prehistoric groups into various parts of Southeast Asia. In Mainland Southeast Asia, this distribution is entirely in keeping with the dispersal of rice, as established by Higham and $\mathrm{Lu}$ (1998).

Until recently, biconical whorls were defined as atypical for China, belonging to the Tanshishan culture, a relatively late Neolithic culture in southeast China (Kuhn 1988; Cameron 2001, 2002, 2007). However, recent excavations in the upper layers of the early Neolithic site of Tianluoshan (5000-2500 BC) in Zhejiang Province, which belongs to the Hemudu culture, have also produced biconical whorls, as well as evidence for the some of the oldest rice fields in China (Zheng et al 2009; Fuller et al. 2009). Biconical whorls then continued in the archaeological record in the above-mentioned Tanshishan sites (Fujian Province) and in many Neolithic sites in Taiwan. Despite the fact that prehistoric spindle whorls are relatively rare in the archaeological record of the Philippines, biconical types have also been found on Luzon at Arku Cave (Thiel 1986-7a), Magapit (Aoyagi et al. 1993) and Nagsabaran (Cameron in Hung 2008), and at Linaminan on Palawan Island (Cameron 2007).

Other morphological features link the whorls in the Batanes assemblage to Neolithic examples from the Philippines. For example, the complete whorl from Anaro 4 (Fig. 7.2 C) compares favourably in material composition, size and weight with a sub-biconical whorl excavated by Shutler from the Neolithic site of Andarayan in the Cagayan Valley, Luzon (Fig. 7.2 D). The Andarayan site also produced evidence for a presence of rice chaff in pottery (Snow et al. 1986).

The stamped decorative technique that distinguishes the whorls in the Batanes assemblage first occurs on spindle whorls from Tianluoshan, and continues in the archaeological record on whorls from the type site of Hemudu (Cameron 2002). While the meaning of the stamped motifs remains obscure, it seems far from coincidental that stamping was also used to decorate biconical whorls at Tanshishan sites in southeast China and across the Taiwan Straits in late Neolithic Beinan phase sites on Taiwan. The elaboration of this technique into configurations of stamped circles also distinguished the decorated Batanes pottery (1200-500 BC) found at Anaro, Savidug and Sunget.

Significantly, most whorls found in Batanes belong to Phase 2 of the Batanes sequence, where they occur with nephrite and slate from Taiwan. The relatively small number of whorls at the sites discussed does not indicate intensification of textile production for trade or exchange, but implies domestic production at the household level.

\section{Can the prehistoric spindle whorls from Batanes be linked to any contemporary ethnographic groups?}

Although the Philippines are better known for traditional textiles woven using knotted or reeled fibres from Musa textilis (abaca) and Ananas comosus (pineapple), or imported pre-spun cotton, spindle whorls have also long been used by several ethnographic groups. The Banaue people of Ifugao Province use the drop spindle to spin bark fibres (Milgram 2007). The National Museum of the Philippines houses a biconical whorl from Abra Province which belonged to Tinguian 
spinners. The usage of the hand spindle by these groups was also recorded ethnographically (Cooper-Cole 1915), and historical records also indicate that Bontok Igorots spun tree cotton (probably kapok from Ceiba petandra) with hand spindles (Jenks 1905). Significantly, these recent and contemporary spinning groups (Banaue, Igorot, Tinguian) are wet-rice cultivators from provinces close to the Cagayan Valley, where prehistoric spindle whorls have been found. There can be little doubt from the ethnographic and archaeological evidence that spinning was introduced into the northern Philippines Provinces (Batanes Islands and the Cagayan Valley) with rice during the Neolithic period.

\section{What fibres were spun with these prehistoric tools?}

The question concerning the fibres that were spun remains hypothetical. The only extant archaeological textile found to date in the Philippines is a $12^{\text {th }}$ century unspun abaca cloth from Banton Island currently being analysed by Quizon and Cameron (2009). Previously, it has been suggested (Cameron 2002; Cameron in Bellwood et al. 2003; Cameron and Mijares 2006) that fibres from Musa sp. could also have been spun with the prehistoric whorls found in the Philippines. There were several reasons for this suggestion. During fieldwork, the author's informants stressed that spinners are extraordinarily pragmatic and use a wide range of fibres with choice contingent on availability. Textiles woven from Musa textilis (abaca) have been known in South China for more than 2000 years (Kuhn 1988). Interpretation is difficult because this fibre is not spun with whorls in the Philippines today, being simply twisted or knotted, processes which represent a different stage in the development of textile technology. However, $M$. textilis is reeled in Iloilo province (Krieger 1942: Plate 9.2), using a simple reeling machine of the type which replaced the spindle whorl in China during the Han dynasty (206 BC-AD 220). In addition, Navarette reported the usage of $M$. textilis (Manila hemp) for black "hemp" rigging and cables on the island of Mindoro in the $17^{\text {th }}$ century (Cummins 1962:81). Known as Manila hemp, this fibre's tensile strength makes it the world's premium natural cordage fibre for maritime purposes. Moreover, experiments conducted with abaca by contemporary craft persons in other parts of the world have demonstrated that the fibres spin very well.

We know with greater certainty that Pueraria thunbergiana (bean creeper) was an important fibreproducing plant during the prehistoric period in South China. Shanghai textile scholars have identified the species in archaeological textiles dating back to the $4^{\text {th }}$ millennium BC. Considered to be native to East Asia, its wild progenitor, Pueraria thomsonii, grows prolifically in the southeast coastal provinces of China (Kuhn 1988). The author has also observed this species growing near the archaeological site of Hemudu in Zhejiang Province, where evidence is first found for the back strap loom that is represented throughout Southeast Asi.

Another fibre-producing plant that may have been used in the Batanes is Broussonetia papyrifera (paper mulberry). In southern China, paper mulberry fibres were obtained and processed in the same way as abaca - stripped, boiled, and split before being spliced and spun. The origins and early distribution of the paper mulberry is well documented (Matthews 1996), and the species was central to Austronesian dispersals in Island Southeast Asia and Polynesia (Bellwood 2007). But discussion of it is usually confined to the manufacture of beaten bark cloth (Cameron 2006, 2008). However, Milgram's (2007) research has clearly established that contemporary Banuag from Ifugao use paper mulberry for both beaten bark cloth and spun and woven textiles.

The fibre-producing plant Hibiscus tiliaceae has also been identified in the Batanes Islands, as well as along seashores and tidal estuaries in the Philippines generally. Given the range of possibilities, Neolithic spinners may have introduced a range of suitable textile fibres into Island Southeast Asia during this period. 
Previously, the author has suggested that Boehmeria nivea (ramie) could have been spun using biconical whorls. During the prehistoric and early historic periods in South China, ramie was the dominant textile fibre, whereas Cannabis sativa (hemp) was the fibre of the north. Extant remains of ramie textiles have been found at sites in southeast China (Kuhn 1988) and Vietnam (Cameron 2008), and in association with biconical whorls at Tanshishan sites in Fujian Province (Cameron 2000, 2002). I have observed the usage of biconical whorls to spin ramie fibres on Hainan Island, and botanical research in Batanes has also revealed the presence there of wild ramie, Maoutia setosa Wedd. (Valerio 1995-1997).

The spindle whorl data provide unequivocal evidence for the movement of textile technology into the Batanes from southeast China and Taiwan during the late prehistoric period, around or before $1200 \mathrm{BC}$, and enable us to link the Batanes spinners to specific prehistoric and contemporary cultures. The absence of pottery whorls south of Luzon militates against any introduction of this technology from further south in Island Southeast Asia. The parallels in the spinning data are interpreted as archaeological evidence for population movement rather than as evidence for independent invention, or trade and exchange. Had spinning been invented independently in the Batanes, basic whorl types (flat discs) would be represented rather than biconical forms. Because biconical whorls have a higher moment of inertia than basic types, and spin faster than basic forms, they indicate a presence of spinners with technical knowledge and skill, not novices. 